\title{
Study on Pre-Warning Method of the Lateral Security of Heavy Vehicle in Deteriorative Weather
}

\author{
Zhi-Guo Zhao ${ }^{*}, 1,2$, Min Chen ${ }^{1}$, Nan Chen ${ }^{1}$, Yong-Bing Zhao ${ }^{2}$ and Xin Chen $^{2}$ \\ ${ }^{1}$ School of Mechanical Engineering, Southeast University, Nanjing, China \\ ${ }^{2}$ School of Transportation Engineering, Huaiyin Institute of Technology, Huaian, China
}

\begin{abstract}
The lateral security of heavy vehicle in deteriorative weather is one of the main causes of accidents of vehicles on roads. Road safety has become a subject of great concern to institutions of higher education and scientific research institutions. There are important theoretical and practical significances to explore applicable and effective lateral safety warning methods of heavy vehicles. One of the purposes of this paper is to provide a good theoretical basis for the core technology of heavy vehicle safety features for our country's independent research and development. Aiming at the issue of lateral security of heavy vehicle for road conditions in deteriorative weather, this paper constructs the framework of the lateral security pre-warning system of heavy vehicles based on cooperative vehicle infrastructure. Moreover, it establishes vehicle lateral security statics model through analysis of the force of the car in the slope with section bending and states the parameters of vehicles for no rollover. The side slip is indexed to calculate critical speed of vehicles in a bend. This paper also analyzes the influence of road friction coefficient, the road gradient and the turning radius on the lateral security of the vehicle with critical speed on the asphalt pavement with surface conditions ranging from wet, dry, snowing or icy. The calculation results show that the bad weather road conditions, road friction coefficient and turning radius have obvious influence on the lateral security critical speed. Experimental results indicate that the critical speed error warning is within $4 \%$ and it meets the design requirements.
\end{abstract}

Keywords: Cooperative vehicle infrastructure, Deteriorative weather, Heavy vehicle, Rollover, Side slip, The lateral security.

\section{INTRODUCTION}

Traffic system is a complex system. In the worst weather conditions, road friction decreases, due to which vehicles more often tend to be out of the driver's control $[1,2]$. In heavy trucks, there is a high center of gravity, large loading capacity and the aspect ratio is relatively large. When the vehicles turn onto unfamiliar roads, since the drivers are not familiar with the road information and conditions, excessive speed and unexpected turn radius can cause the vehicles to easily sideslip and rollover [3]. Therefore, environmental information for vehicle safety is very important. As an important part of intelligent traffic system, vehicle-road collaboration infrastructure is very important to improve vehicle safety and realize the sustainable development of transportation system.

Cooperative vehicle infrastructure has become a cuttingedge technology and a research hotspot in the international intelligent transportation field. Europe and the United States and other developed regions promote the study of Propulsion technology positively [4-6]. This paper studied the lateral security of heavy vehicles and made the state parameters of vehicles to avoid rollover and prepares side slip index to calculate critical speed of vehicles in bends, as a means to

*Address correspondence to this author at the School of mechanical engineering, Southeast University, Nanjing, China; Tel: 0517-83559165; Fax: 0517-83559167; E-mails: lnzzg98@163.com,51066347@qq.com simulate lateral security situation of the vehicles in the dry wet or icy asphalt pavement conditions. It also analyzes the influence of road friction coefficient, road gradient and turning radius on the lateral security critical speed under different weather conditions.

\section{THE FRAMEWORK OF THE LATERAL SECURITY PRE-WARNING SYSTEM OF HEAVY VEHICLES BASED ON COOPERATIVE VEHICLE INFRASTRUCTURE}

Fig. (1) represents a systematic diagram of the lateral security pre-warning system of heavy vehicles based on cooperative vehicle infrastructure; the system consists of the roadside equipment, roadside wireless transmitter module, wireless receiver module and vehicle warning system. It broadcasts road information by wireless transmitter module installed on the roadside. This information is transmitted to the vehicle mounted unit, which in turn transmits back the vehicle information and real-time speed of the vehicle to the road side wireless transmitter module. It calculates the safest bend speed limit depending on the weather conditions and informs the driver of the optimum approach speed limit near the bend.

\section{CALCULATION OF THE LATERAL SECURITY CRITICAL SPEED OF VEHICLES PARAMETERS CONSIDERING THE EFFECT OF ROAD}

At present, dynamics model for rollover/sideslip generally adopts the vehicles as a quasi-static model having 
a rigid body. For the calculation of critical speed for the lateral security of vehicles on a bend, the model ignores deformation of vehicle suspension and flexible deformation of tires [7, 8]. The analysis of literature [9] shows that comparison of the rigid vehicles with suspension vehicles demonstrates the rollover thresholds of both of them as being close. Therefore, this paper adopts the static model and neglects suspension deformation, as shown in Fig. (2). In the diagram, $\mathrm{F}_{\mathrm{C}}$ is the centrifugal force, $\mathrm{F}_{\mathrm{f}}$ is the lateral friction, $\theta$ is the road transverse slope angle, $B$ is the distance between the center of the two tires on either side of the vehicle, $h_{g}$ is the height of the center of gravity, $G$ is the total gravity of vehicle.

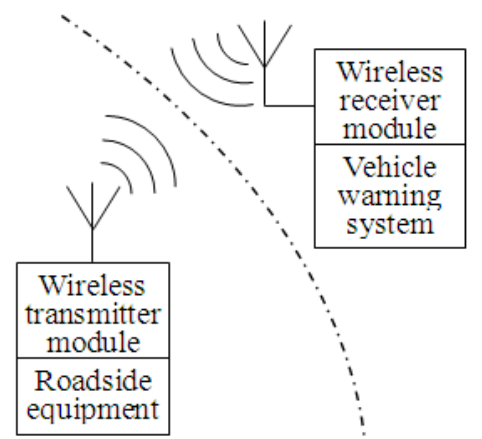

Fig. (1). The framework of the lateral security pre-warning system of heavy vehicles based on cooperative vehicle infrastructure.

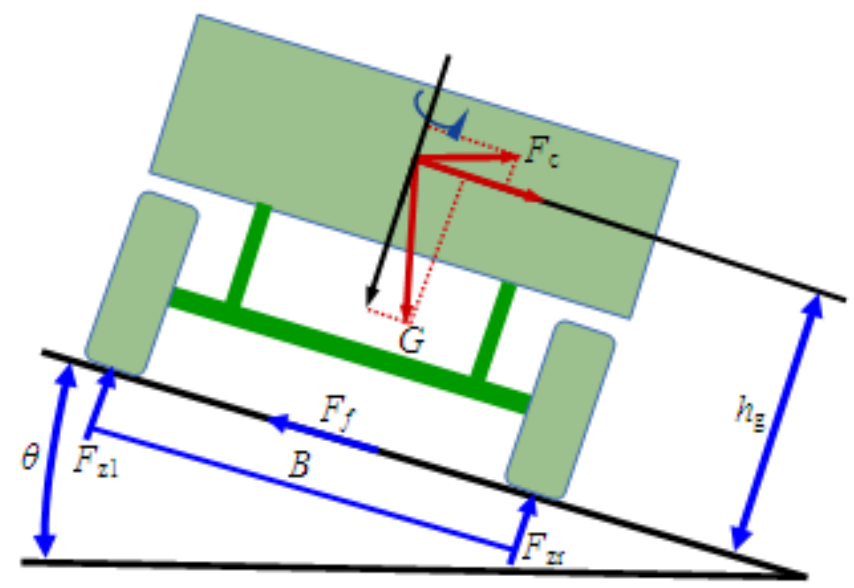

Fig. (2). Force analytical graph of heavy truck on the side slope when steering.

\subsection{Critical Speed of Index for No Sideslip}

According to quasi-static model of vehicle shown in Fig. (2), the necessary condition of no sideslip is that vehicle lateral force is less than the lateral friction, that is

$$
F_{c} \cos \theta+G \sin \theta \leq F_{f}=\left(G \cos \theta-F_{c} \sin \theta\right) f
$$

where, $F_{c}=\frac{m u^{2}}{R}, u$ is the speed of vehicle, $R$ is the radius of bend, $f$ is the road friction coefficient.

Inserting $F_{c}$ into formula (1), we can get: $u_{c h \max } \leq \sqrt{\frac{g R(f-\tan \theta)}{f \tan \theta+1}}$

\subsection{Critical Speed of Index for No Rollover}

According to quasi-static model of vehicle shown in Fig. (2), the vehicle does not rollover while vehicle rollover torque is less than the stability torque, that is:

$\left(F_{c} \cos \theta+G \sin \theta\right) h_{g} \leq \frac{\left(G \cos \theta-F_{c} \sin \theta\right) B}{2}$

Feeding $F_{c}$ into formula (3), we can get:

$u_{c f \max } \leq \sqrt{\frac{g R\left(B-2 h_{g} \tan \theta\right)}{2 h_{g}+B \tan \theta}}$

\subsection{Analysis of Critical Speed of Driving Safety}

Comparing roll with sideslip, the consequences are more serious. Therefore, considering the driving safety, the slip should occur before the rollover, that is:

$u_{c h \max } \leq u_{c f \max }$

When the vehicle is in sideslip, the speed will not increase, and the rollover phenomenon would not happen. Inserting formula (2) and formula (4) into formula (5), we can get:

$\sqrt{\frac{g R(f \cos \theta-\sin \theta)}{f \sin \theta+\cos \theta}} \leq \sqrt{\frac{g R\left(B \cos \theta-2 h_{g} \sin \theta\right)}{2 h_{g} \cos \theta+B \sin \theta}}$

That is:

$$
f \leq \frac{B}{2 h_{g}} \cdot \frac{1+\operatorname{tg}^{2} \theta}{1-\operatorname{tg}^{2} \theta}
$$

For general dry asphalt pavement, $f$ is in the range of 0.6-0.8. Therefore, in the process of using and designing vehicles, the height of the center of gravity should be lowered in order to meet the requirements of formula (7).

\section{ANALYSIS OF INFLUENCE OF ROAD PARAMETERS ON THE LATERAL SECURITY CRITICAL SPEED OF VEHICLES}

\subsection{Basic Parameters}

At full load, the height of the center of gravity, $h_{g}$, is $1360 \mathrm{~mm}, \mathrm{~B}$ is $1860 \mathrm{~mm}$, acceleration of gravity, $\mathrm{g}$, is $9.81 \mathrm{~m} / \mathrm{s}^{2}$, the road transverse slope angle $\theta$ is $1.15^{\circ}$, radius of curve $\mathrm{R}$ is $125 \mathrm{~m}$. Road friction coefficient in deteriorative weather is shown in Table $\mathbf{1}$ below.

Table 1. Road friction coefficient of road conditions in deteriorative weather.

\begin{tabular}{|c|c|}
\hline Weather Conditions & Friction Coefficient \\
\hline \hline Dry asphalt pavement & 0.6 \\
\hline Rainy pavement & 0.4 \\
\hline Snowy pavement & 0.28 \\
\hline Icy pavement & 0.18 \\
\hline
\end{tabular}




\subsection{Influence of Road Friction Coefficient on the Lateral Security Critical Speed of Vehicles}

Inserting the basic parameters of road and vehicles into formula (2) and formula (4), the critical speed for rollover and sideslip of heavy vehicles in the road conditions of deteriorative weather can be obtained as shown in Table 2 .

As the formula (5) shows, the sideslip must be controlled if the rollover is to be prevented, so in order to make the vehicle turn safely, lateral security critical speed should be equal to sideslip critical speed. As shown in Table 2, with the increase of road friction coefficient, the lateral security critical speed of vehicles is greater.

\subsection{Influence of Transverse Slope of Road on the Lateral Security Critical Speed of Vehicles}

In order for the rain water to drain, pavement and road should have certain transverse slopes; the slope values were $1 \%$, $1.5 \%, 2 \%, 2.5 \%, 3 \%$ and $3.5 \%$. Taking pavement of rainy, snowy and icy roads for example, the influence of transverse slope on the critical speed is shown in Tables 3-5.
As Tables 3-5 show that with the increase of transverse slope and decrease of road friction coefficient, the lateral security critical speed of vehicle decreases gradually.

\subsection{Influence of the Road Turning Radius on the Lateral Security Critical Speed of Vehicles}

Different roads have different requirements for the design of turning radius; the values of turning radius were $30 \mathrm{~m}$, $60 \mathrm{~m}, 125 \mathrm{~m}, 250 \mathrm{~m}$ and $500 \mathrm{~m}$. Taking pavement of rainy, snowy and icy roads for example, the influence of turning radius on the critical speed is shown in Tables 6-8.

Tables $\mathbf{6}$ and $\mathbf{8}$ show that with the increase of turning radius, the lateral security critical speed of vehicle increases and with the decrease of road friction coefficient, the lateral security critical speed of vehicle decreases.

The model and pre-warning method above will be verified by remote control vehicle model test. Taking dry asphalt pavement as an example, pilot test and theoretical analysis of lateral security critical speed under different turning radiuses were analyzed. The results show that critical speed error warning is within $4 \%$ and it meets the design requirements.

Table 2. The critical speed for rollover and sideslip of heavy vehicles in the road conditions of deteriorative weather.

\begin{tabular}{|c|c|c|c|}
\hline Friction Coefficient & $\begin{array}{c}\text { Critical Speed for Rollover } \\
(\mathbf{k m} / \mathbf{h})\end{array}$ & $\begin{array}{c}\text { Critical Speed for Sideslip } \\
(\mathbf{k m} / \mathbf{h})\end{array}$ & $\begin{array}{c}\text { The Lateral Security Critical } \\
\text { Speed (km/h) }\end{array}$ \\
\hline \hline 0.6 & 95.4 & 102 & 95.4 \\
\hline 0.4 & 77.4 & 102 & 77.4 \\
\hline 0.28 & 64.1 & 102 & 64.1 \\
\hline 0.18 & 50.3 & 102 & 50.3 \\
\hline
\end{tabular}

Table 3. Influence of transverse slope of road on the lateral security critical speed of vehicles on the rainy pavement.

\begin{tabular}{|c|c|c|c|}
\hline Transverse Slope & $\begin{array}{c}\text { Critical Speed for Rollover } \\
(\mathbf{k m} / \mathbf{h})\end{array}$ & $\begin{array}{c}\text { Critical Speed for Sideslip } \\
\mathbf{( k m / h )}\end{array}$ & $\begin{array}{c}\text { The Lateral Security Critical } \\
\text { Speed (km/h) }\end{array}$ \\
\hline \hline 1.0 & 78.6 & 103.1 & 78.6 \\
\hline 1.5 & 78.0 & 102.6 & 78.0 \\
\hline 2.0 & 77.4 & 102.0 & 77.4 \\
\hline 2.5 & 76.8 & 101.5 & 76.8 \\
\hline 3.0 & 76.2 & 100.9 & 76.2 \\
\hline 3.5 & 75.6 & 100.4 & 75.6 \\
\hline
\end{tabular}

Table 4. Influence of transverse slope of road on the lateral security critical speed of vehicles on the snowy pavement.

\begin{tabular}{|c|c|c|c|}
\hline \begin{tabular}{c} 
Transverse Slope \\
\hline 1.0
\end{tabular} & $\begin{array}{c}\text { Critical Speed for Rollover } \\
\mathbf{( k m} / \mathbf{h})\end{array}$ & $\begin{array}{c}\text { Critical Speed for Sideslip } \\
(\mathbf{k m} / \mathbf{h})\end{array}$ & $\begin{array}{c}\text { The Lateral Security Critical } \\
\text { Speed (km/h) }\end{array}$ \\
\hline \hline 1.5 & 65.4 & 103.1 & 65.4 \\
\hline 2.0 & 64.8 & 102.6 & 64.8 \\
\hline 2.5 & 64.1 & 102.0 & 64.1 \\
\hline 3.0 & 63.4 & 101.5 & 63.4 \\
\hline 3.5 & 62.8 & 100.9 & 62.8 \\
\hline
\end{tabular}


Table 5. Influence of transverse slope of road on the lateral security critical speed of vehicles on the icy pavement.

\begin{tabular}{|c|c|c|c|}
\hline Transverse Slope & $\begin{array}{c}\text { Critical Speed for Rollover } \\
(\mathbf{k m} / \mathbf{h})\end{array}$ & $\begin{array}{c}\text { Critical Speed for Sideslip } \\
\mathbf{( k m} / \mathbf{h})\end{array}$ & $\begin{array}{c}\text { The Lateral Security Critical } \\
\text { Speed (km/h) }\end{array}$ \\
\hline \hline 1.0 & 51.9 & 103.1 & 51.9 \\
\hline 1.5 & 51.1 & 102.6 & 51.1 \\
\hline 2.0 & 50.3 & 102.0 & 50.3 \\
\hline 2.5 & 49.5 & 101.5 & 49.5 \\
\hline 3.0 & 48.7 & 100.9 & 48.7 \\
\hline 3.5 & 47.9 & 100.4 & 47.9 \\
\hline
\end{tabular}

Table 6. Influence of turning radius on the lateral security critical speed of vehicles on the rainy pavement.

\begin{tabular}{|c|c|c|c|}
\hline Turning Radius & $\begin{array}{c}\text { Critical Speed for Rollover } \\
(\mathbf{k m} / \mathbf{h})\end{array}$ & $\begin{array}{c}\text { Critical Speed for Sideslip } \\
\mathbf{( k m / h )}\end{array}$ & $\begin{array}{c}\text { The Lateral Security Critical } \\
\text { Speed (km/h) }\end{array}$ \\
\hline \hline 30 & 37.9 & 50.0 & 37.9 \\
\hline 60 & 53.6 & 70.7 & 53.6 \\
\hline 125 & 77.4 & 102.0 & 77.4 \\
\hline 250 & 109.5 & 144.3 & 109.5 \\
\hline 500 & 154.8 & 204.0 & 154.8 \\
\hline
\end{tabular}

Table 7. Influence of turning radius on the lateral security critical speed of vehicles on the snowy pavement.

\begin{tabular}{|c|c|c|c|}
\hline Turning Radius & $\begin{array}{c}\text { Critical Speed for Rollover } \\
(\mathbf{k m} / \mathbf{h})\end{array}$ & $\begin{array}{c}\text { Critical Speed for Sideslip } \\
(\mathbf{k m} / \mathbf{h})\end{array}$ & $\begin{array}{c}\text { The Lateral Security Critical } \\
\text { Speed }(\mathbf{k m} / \mathbf{h})\end{array}$ \\
\hline \hline 30 & 31.4 & 50.0 & 31.4 \\
\hline 60 & 44.4 & 70.7 & 44.4 \\
\hline 125 & 64.1 & 102.0 & 64.1 \\
\hline 250 & 90.7 & 144.3 & 90.7 \\
\hline 500 & 128.2 & 204.0 & 128.2 \\
\hline
\end{tabular}

Table 8. Influence of turning radius on the lateral security critical speed of vehicles on the icy pavement.

\begin{tabular}{|c|c|c|c|}
\hline Turning Radius & $\begin{array}{c}\text { Critical Speed for Rollover } \\
(\mathbf{k m} / \mathbf{h})\end{array}$ & $\begin{array}{c}\text { Critical Speed for Sideslip } \\
(\mathbf{k m} / \mathbf{h})\end{array}$ & $\begin{array}{c}\text { The Lateral Security Critical } \\
\text { Speed (km/h) }\end{array}$ \\
\hline \hline 30 & 24.7 & 50.0 & 24.7 \\
\hline 60 & 34.9 & 70.7 & 34.9 \\
\hline 125 & 50.3 & 102.0 & 50.3 \\
\hline 250 & 71.2 & 144.3 & 71.2 \\
\hline 500 & 100.7 & 204.0 & 100.7 \\
\hline
\end{tabular}

\section{CONCLUSION}

1) This paper constructed the framework of the lateral security pre-warning system of heavy vehicles based on cooperative vehicle infrastructure. The system consisted of the roadside equipment, roadside wireless transmitter module, wireless receiver module and vehicle warning system.
2) Vehicles for no rollover and side slip were indexed to calculate critical speed of vehicles on road bends.

3) Analysis on the influence of road friction coefficient, road gradient and turning radius on the lateral security critical speed in the pavement condition of asphalt pavement with either dry rainy, snowy or icy surface was conducted. The simulation results show that in the bad weather road conditions, road friction 
coefficient and turning radius have obvious influence on the lateral security critical speed.

\section{CONFLICT OF INTEREST}

The authors confirm that this article content has no conflict of interest.

\section{ACKNOWLEDGEMENTS}

Research was partially sponsored by supported by the National Natural Science Foundation of China(Grant No.51205151), China Postdoctoral Science Foundation (Grant No.2013M5312471), Postdoctoral research grants program of Jiangsu Province (Grant No.1301096C) and The peak of six personnel of Jiangsu Province(Grant No.2013ZBZZ-020).

\section{REFERENCES}

H. Jie, and L. Xia, "Influence of road condition on running safety in atrocious weather", Journal of Traffic and Transportation Engineering, vol. 1, no. 11, pp. 58-63, 2011.

[2] T. R. Neuman, R. Pfefer, and K. L. Slacka, K. K. Hardy, K. Lacy, and C. Zegeer, A guide for addressing run-off-road collisions.
Washington DC: American Association of State Highway and Tranportation Officials, 2003.

[3] Z. Zhiguo, and W. Dongdong, "Research status and development trend of side tumbing pre-warning vehicle", Journal of Hebei University of Science and Technology, vol. 2, no. 34, pp.108-112 2013.

[4] S.E. Shladover, "Progressive Deployment Steps Leading Toward an Automated Highway System (AHS)", Transportation Research Record No. 1727, Transportation Research Board: Washington DC, pp. 154-161, 2000.

[5] R. Bishop, "Intelligent vehicle applications worldwide", Intelligent Systems and their Applications, IEEE, vol. 1, no. 15, pp. 78-81, 2000 .

[6] W. Yunpeng, Y. Zhenguo, and X. Haiying, et al. Cooperative traffic alarming method based on epidemic model. Journal of Beijing University of Aeronautics and Astronautics, vol. 5, no. 37, pp. 515-518, 2011

[7] P. Jiabin, and W. Dalei, "Probability evaluating method of bridge deck side wind effects on driving safety", China Journal of Highway and Transport, vol. 4, no. 19, pp. 59-64, 2006.

[8] Y. Qunli, C. Xujun, and J. Zhaobing, "Analysis of safety wind velocity of driving on sea-cross bridge based on target of no sideslip", Journal of PLA University of Science and Technology, vol. 4, no. 9, pp. 373-377, 2008

[9] L. Jing, Z. Dongdong, G. Tengfeng, "Analysis for influence of large vehicles lateral stability on ultimate horizontal curve radius of highway design," China Journal of Highway and Transport, vol. Z1, no. 23, pp. 42-46, 2010. 